\title{
APPLIANCE
}

\section{A SNARE TO REDUCE POST-EXCISIONAL HAEMORRHAGE*}

\author{
BY \\ JOHN Foster \\ Leeds
}

PRIMARY orbital haemorrhage after excision of the eye may delay completion of the operation for 5 to 15 minutes, may necessitate a tight bandage, and may recur as secondary haemorrhage in the ward. A haematoma may produce a reaction leading to the loss of an orbital implant.

Amongst the simpler antidotes employed to-day are rotation of the globe by traction on the stumps of the tendons prior to cutting the optic nerve, diathermic section of the nerve, hot irrigation, and pressure by hot packs or ball-shaped haemostats afterwards. Wright (1930) introduced the use of Eves' tonsil snare, subsequently discarding this for curved orbital forceps (which crushed the optic pedicle) which he found more effective. Kirby (1945), agreeing with Wright that snares are liable to open Tenon's capsule, prefers to use hot packs only. Myers (1950), advocating the use of snares, claims that they are less liable to open Tenon's capsule than curved scissors. My own experience with orbital clamps, hot packs, and irrigation has been discouraging.

Various tonsil snares devised since 1938 (including the original Eves' snare kindly given me by Wright) have proved unreliable, as one of the following difficulties often occurs :

(1) the wire breaks,

(2) the wire becomes detached at one end from the loop in the handle,

(3) the optic nerve either cannot be cut without the exertion of force, which hurts the operator's hand, or it cannot be cut at all.

The small and extremely simple snare (made to my design by Down Bros.) shown in the Figure (overleaf) has none of these faults and has proved effective so far in every case in which it has been used in the last few months. Although this snare will cut the "obliques" and the nerve together, it is better to cut 
these muscles with scissors in any case where the eye has been perforated or incised, as the increased pressure exerted bursts the eye. A long section of optic nerve can be obtained by pushing the snare as far back as possible and simultaneously levering the eye forward with the spoon-like spatula of Trelat (or Weltz). Although the wire (stainless steel SWG26) can be used several times, it may become kinked and is best replaced after each operation.

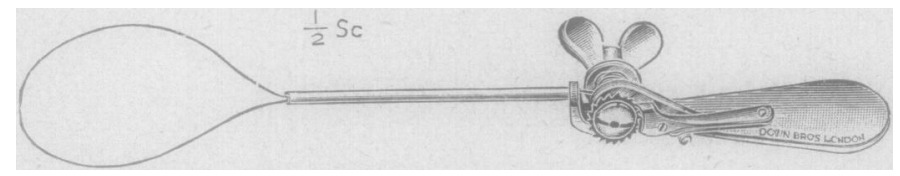

Figure.--Excision snare half scale. The wire loop is tightened by rotating the butterfly thumb-screw, pressure being maintained by the ratchet.

Sume users of this snare have constricted the optic nerve with it and have then used scissors to divide the nerve between the constriction and the globe. It must be emphasized that the snare should be tightened rapidly until resistance is felt, and then slowly until the nerve is divided completely.

As other advocates of snares for excision have indicated, postexcisional haemorrhage is negligible after successful use of the instrument, the implant can be inserted without delay, tight bandaging is unnecessary, and convalescence is greatly shortened.

\section{REFERENCES}

KIRBY, D. B. (1945). Arch. Ophthal., Chicago, 34, 1.

Myers, R. H. (1950). Amer. J. Ophthal., 33, 144.

Wrighit, R. E. (1930). Ind. med. Gaz., 65, 550. 